\title{
Desempenho e Parâmetros Sangüíneos de Eqüinos em Crescimento Submetidos a Dietas com Diferentes Níveis de Farelo de Canola ${ }^{1}$
}

\author{
Kátia de Oliveira ${ }^{2}$, Carlos Eduardo Furtado ${ }^{3}$, Elisa Pereira da Graça ${ }^{4}$
}

\begin{abstract}
RESUMO - Utilizando potros, avaliaram-se dietas em que a proteína do farelo de soja foi substituído em diferentes níveis (0; 35; 65 e $100 \%$ ) pela do farelo de canola. As rações foram isoprotéicas ( $17 \%$ PB) e isocalóricas ( $4200 \mathrm{kcal} / \mathrm{kg}$ ). Foram utilizados 16 eqüinos da raça Mangalarga, sendo oito machos e oito fêmeas, com média de dez meses e $218 \mathrm{~kg}$ PV inicial, consumindo um total de $2,5 \%$ PV, na matéria seca (MS). A dieta era composta por $40 \%$ de volumoso e $60 \%$ de concentrado. O delineamento experimental utilizado foi em blocos ao acaso, considerando quatro blocos e quatro tratamentos. Não se verificou efeito dos tratamentos sobre as variáveis de desempenho (ganho diário de peso vivo, altura na cernelha, perímetro torácico e perímetro da canela) e parâmetros sangüíneos (glicose e uréia) dos potros em crescimento. Nos concentrados para potros dos 9 a 11,5 meses de idade, o farelo de soja pode ser substituído pelo farelo de canola.
\end{abstract}

Palavras-chave: crescimento, farelo de canola, potros

\section{Performance and Blood Parameters of Growing Equine Fed Diets with Different Levels of Canola Meal}

\begin{abstract}
Diets composed by four different levels (0; 53; 65 and 100\%) of canola meal replacing soybean meal crude protein (CP) were evaluated using foals. The diets were isoproteic ( $17 \% \mathrm{CP})$ and isocaloric ( $4200 \mathrm{kcal} / \mathrm{kg}$ ). Sixteen Managalarga breed foals, eight males and eight females, averaging 10 months and $218 \mathrm{~kg} \mathrm{LW}$, fed a total intake of $2.5 \% \mathrm{LW}$ on dry matter (DM) basis were used. The diet was composed by 60:40 forage to concentrate ratio. A completely block experimental design, with four blocks and four treatments, was used. There were no effect of treatments on the performance variables (average daily gain, wither height, heart girth and cannon bone circumference) and blood parameters (glucose and urea) of growing foals. In the concentrate for growing foals from 9 to 11.5 months old, the soybean meal can be replaced by canola meal.
\end{abstract}

Key Words: canola meal, foals, growth

\section{Introdução}

Os concentrados para cavalos são baseados, tradicionalmente, em três alimentos: milho, farelo de soja e farelo de trigo. Isto decorre, entre outros fatores, em função de poucas pesquisas existentes, visando oferecer soluções alternativas para substituir estes ingredientes. Por outro lado, os efeitos da substituição de alimentos têm sido estudados largamente, nas outras espécies, como ruminantes, aves e suínos. Muitos experimentos têm sido realizados com alimentos tradicionalmente utilizados nas rações desta espécie (HINTZ et al., 1979; SAASTAMOINEN e KOSKINEN, 1993; THOMPSON, 1995; CARVALHO, 1995; WHITAKER et al., 1995; WHITAKER e CARVALHO 1997), mas pouca informação existe a respeito de outras fontes potenciais, para compor rações para os cavalos.

O farelo de canola, subproduto da extração do óleo, tem sido estudado em outros países como fonte protéica alternativa e promissora para ração animal, devido ao seu custo inferior às fontes tradicionais. A composição química média é de $38,3 \%$ de proteína bruta (PB) e energia bruta (EB) de $4700 \mathrm{kcal} / \mathrm{kg}$ (BELL, 1993) e, em comparação ao farelo de soja, apresenta níveis inferiores de PB e lisina e níveis superiores de aminoácidos sulfurados (BELL e KEITH, 1991 e CASTELL e CLIPLEF, 1993). Porém, a quantidade de lisina presente no farelo de canola supre os requerimentos nutricionais desse aminoácido para cavalos em crescimento (LEWIS, 1995).

\footnotetext{
${ }^{1}$ Parte da Dissertação de Mestrado apresentada à UEM pelo primeiro autor.

2 Professora do Departamento de Zootecnia - UNIMAR - 17.502-000 - Marília - SP.

3 Professor do Departamento de Zootecnia - UEM - 87.020-900 - Maringá - PR. E.mail:cefurtado@uem.br

${ }^{4}$ Estudante de Graduação do Curso de Zootecnia, UEM. Bolsista PIBIC - CNPq.
} 
Analisando o efeito da substituição do farelo de soja pelo farelo de canola para cavalos, SUTTON e STREDWICK (1979) observaram que nenhuma diferença significativa ocorreu para o consumo de ração, inclusive para o nível de substituição total. As médias de ganho de peso e eficiência alimentar foram similares para todos os grupos, sugerindo que altos níveis de farelo de canola da dieta não prejudicam o crescimento dos eqüinos.

ROGERS et al. (1984) concluíram que o farelo de canola é excelente suplemento protéico para cavalos, com base no bom desempenho e consumo desses animais, alimentados com dietas contendo farelo de canola. Além disso, o farelo de canola pode ser usado como única fonte de proteína para eqüinos em crescimento e os resultados são semelhantes aos do farelo de soja.

Avaliando a substituição do farelo de soja pelo farelo de canola, CYMBALUK (1990) indicou o nível de substituição total (100\%) para potros de 6 a 12 meses de idade, pois não se verificou queda no ganho de peso.

Conforme o exposto anteriormente, nota-se que resultados positivos têm sido alcançados na alimentação de monogástricos, no que se refere à utilização do farelo de canola em substituição ao farelo de soja, como ingrediente de rações. Todavia, inexistem pesquisas, em nosso país, avaliando o farelo de canola para eqüinos. Portanto, o objetivo do presente trabalho foi avaliar a substituição parcial e total da proteína bruta do farelo de soja pelo farelo de canola, para eqüinos, por meio do estudo de desempenho e parâmetros sangüíneos.

\section{Material e Métodos}

Foram utilizados 16 eqüinos, oitos machos e oito fêmeas, com média de nove meses e peso vivo (PV) de $218 \mathrm{~kg}$. O delineamento experimental utilizado foi em blocos ao acaso, considerando quatro blocos e quatro tratamentos, utilizando o peso médio inicial como covariável. Os tratamentos consistiram de quatro níveis $(0 ; 35 ; 65$ e 100\%) de substituição da proteína do farelo de soja pela do farelo de canola.

A composição química dos ingredientes, centesimal e química das dietas experimentais, encontra-se nas Tabelas 1, 2 e 3, respectivamente.

A quantidade de alimento oferecida aos animais foi estabelecida segundo as recomendações do NUTRITION RESEARCH COUNCIL - NRC (1989) e OTT (1995), visando atender as exigências nutricionais para a categoria. As dietas foram fornecidas em três refeições $(8,12$ e 17 h), após as quais os animais permaneceram em pastagens de tifton. A ingestão total de alimentos foi composta por $60 \%$ de concentrado e $40 \%$ de pasto de tifton, na MS ingerida/animal/dia, perfazendo um total de ingestão, na MS, de 2,5\% PV. O consumo de MS foi corrigido a cada 15 dias e amostras do alimento foram coletadas no início e final de cada período (15 dias) e processadas segundo metodologia proposta pela ASSOCIATION OF OFFICIAL ANALYTICAL CHEMIST - AOAC (1980).

O experimento consistiu de um período pré-experimental de 15 dias, visando adaptar os animais ao manejo, às instalações e ao alimento oferecido. $\mathrm{O}$ período experimental teve duração de 75 dias, cons-

Tabela 1 - Composição química dos ingredientes $(\% \mathrm{MS})^{1}$ Table 1 - Chemical composition of the ingredients (\% DM) ${ }^{1}$

\begin{tabular}{|c|c|c|c|c|c|c|c|}
\hline $\begin{array}{l}\text { Alimento } \\
\text { Feed }\end{array}$ & $\begin{array}{c}\mathrm{MS}(\%) \\
D M\end{array}$ & $\begin{array}{c}\mathrm{PB}(\%) \\
C P\end{array}$ & $\begin{array}{c}\mathrm{EE}(\%)^{2} \\
E E\end{array}$ & $\begin{array}{c}\mathrm{FB}(\%)^{3} \\
C F\end{array}$ & $\begin{array}{c}\mathrm{FDN}(\%)^{4} \\
N D F\end{array}$ & $\begin{array}{c}\mathrm{FDA}(\%)^{5} \\
A D F\end{array}$ & $\begin{array}{c}\mathrm{EB}(\mathrm{kcal} / \mathrm{kg}) \\
G E\end{array}$ \\
\hline $\begin{array}{l}\text { Milho } \\
\text { Corn grain }\end{array}$ & 89,64 & 9,45 & 4,24 & 1,96 & 10,46 & 4,58 & 4460 \\
\hline $\begin{array}{l}\text { Farelo de soja } \\
\text { Soybean meal }\end{array}$ & 91,31 & 42,58 & 2,27 & 6,60 & 17,87 & 11,87 & 4547 \\
\hline $\begin{array}{l}\text { Farelo de trigo } \\
\text { Wheat meal }\end{array}$ & 91,17 & 16,04 & 4,07 & 8,85 & 41,70 & 12,89 & 4487 \\
\hline $\begin{array}{l}\text { Farelo de canola } \\
\text { Canola meal }\end{array}$ & 88,89 & 41,62 & 1,44 & 10,19 & 32,26 & 23,64 & 4670 \\
\hline $\begin{array}{l}\text { Tifton } \\
\text { Tifton hay }\end{array}$ & 91,74 & 8,12 & 1,94 & 32,50 & 75,19 & 42,27 & 4284 \\
\hline
\end{tabular}

\footnotetext{
1 Dados obtidos no laboratório de Análise de Alimentos e Nutrição Animal/DZO/UEM.

$2 \mathrm{EE}=$ extrato etéreo; ${ }^{3} \mathrm{FB}=$ fibra bruta; ${ }^{4} \mathrm{FDN}=$ fibra em detergente neutro; ${ }^{5} \mathrm{FDA}=$ fibra em detergente ácido.

1 Data obtained from Feed Analysis and Animal Nutrition Lab/DZO/UEM.

$2 E E=$ eter extract; ${ }^{3} \mathrm{CF}=$ crude fiber; ${ }^{4} \mathrm{NDF}=$ neutral detergent fiber; $A D F=$ acid detregent fiber.
} 
176 Rev. bras. zootec.

Tabela 2 - Composição centesimal das dietas experimentais $(\% \text { da MS })^{1}$

Table 2 - Percentage composition of the experimental diets $(\% \text { of } D M)^{1}$

\begin{tabular}{lcccc}
\hline Ingrediente & $0-\mathrm{FC}$ & $35-\mathrm{FC}$ & $65-\mathrm{FC}$ & $100-\mathrm{FC}$ \\
Ingredient & $0-C M$ & $35-C M$ & $65-C M$ & $100-C M$ \\
\hline Milho & 60,0 & 60,0 & 60,0 & 59,5 \\
$\begin{array}{l}\text { Corn grain } \\
\text { Farelo de soja }\end{array}$ & 19,0 & 12,5 & 6,5 & - \\
$\begin{array}{l}\text { Soybean meal } \\
\text { Farelo de trigo }\end{array}$ & 17,0 & 17,0 & 17,0 & 17,0 \\
$\begin{array}{l}\text { Wheat meal } \\
\text { Farelo de canola } \\
\text { Canola meal }\end{array}$ & - & 6,5 & 12,5 & 19,5 \\
$\begin{array}{l}\text { Sal } \\
\text { Salt }\end{array}$ & 2,0 & 2,0 & 2,0 & 2,0 \\
Premix ${ }^{1}$ & 2,0 & 2,0 & 2,0 & 2,0 \\
\hline
\end{tabular}

${ }^{1}$ Composição do premix mineral e vitamínico: Ca $185 \mathrm{~g}$; P 180g; Mg 25 g; Zn 5000 mg; Cu 1300 mg; Co 350 mg; Mn 2500 mg; Fe 3000 mg; I 300 mg; Se 20 mg; F 1800 mg; Vit. A 500.000 UI.

tituído por cinco períodos subsequentes de 15 dias, sendo os animais avaliados através dos seguintes parâmetros: ganho diário de peso vivo, aumento da altura na cernelha $(\mathrm{AC})$, aumento do perímetro torácico (PT), aumento do perímetro da canela (PC) e níveis sangüíneos de glicose e uréia.

Os animais foram pesados e mensurados no início do período experimental e, subseqüentemente, a cada 15 dias, bem como vermifugados aos 30, 60 e 90 dias anteriores ao início do experimento.

Todas as pesagens e as mensurações foram efetuadas pela mesma pessoa, durante o período matutino, após jejum de 12 horas. A altura na cernelha foi obtida por intermédio de um hipômetro aplicado sobre o ponto mais alto desta região; o perímetro da canela foi tomado com a fita métrica, passando pelo contorno no centro da região, enquanto o perímetro torácico foi medido com fita métrica colocada logo atrás da cernelha, no nível do nono par de costelas, passando atrás das espáduas e pelo cilhadouro, representando assim o contorno da caixa torácica (LACERDA, 1973).

O monitoramento dos parâmetros sangüíneos, para glicose e uréia, foram realizados, também, a cada quinze dias, coincidindo com as mensurações das características de desempenho. A coleta de sangue foi feita pela veia jugular esquerda, utilizando tubos a vácuo heparinizados e sempre após duas horas do término da última refeição de concentrado. Após a coleta, o sangue foi centrifugado por $20 \mathrm{minu}$ tos e o plasma, separado para as análises de glicose e uréia, segundo as metodologias propostas por TRINDER (1969) e KAPLAN e PESCE (1988), respectivamente.

O modelo estatístico para a análise das características de desempenho e parâmetros sangüíneos foi:

$$
Y_{i j k}=\mu+B_{j}+T_{i}+E_{i j k}
$$

em que $Y_{i j k}$ é observação no animal k submetido ao tratamento i e agrupado no bloco $j ; \mu$, constante geral; $\mathrm{B}_{\mathrm{j}}$, efeitodoblocoj; $\mathrm{j}=1 . . .4 ; \mathrm{T}_{\mathrm{i}}$, efeito do tratamento $\mathrm{i} ; \mathrm{i}=1 . . .4$; $\mathrm{E}_{\mathrm{ijk}}$, erro aleatório associado a cada observação $\mathrm{Y}_{\mathrm{ijk}}$.

A análise estatística das variáveis relativas a desempenho e parâmetros sangüíneos dos animais foi efetuada pela análise de variância para delineamento em blocos ao acaso, com o desdobramento dos graus de liberdade de tratamentos (níveis de canola no concentrado) em polinômios ortogonais (COCHRAN e COX, 1967). Na análise de regressão das características de desempenho e parâmetros sangüíneos, em função dos níveis de farelo de canola, não se considerou o nível zero de canola.

As análises estatísticas foram realizadas utilizando-se o programa Statistical Analysis System (SAS, 1986) e as conclusões foram obtidas, considerando-se nível de significância de $5 \%$.

Tabela 3 - Composição química das dietas experimentais (na matéria seca) ${ }^{1}$

Table 3 - Chemical composition of experimental diets (on DM basis $)^{1}$

\begin{tabular}{lcccc}
\hline Nutriente & $0-\mathrm{FC}$ & $35-\mathrm{FC}$ & $65-\mathrm{FC}$ & $100-\mathrm{FC}$ \\
Nutrient & $0-C M$ & $35-C M$ & $65-C M$ & $100-C M$ \\
\hline $\begin{array}{l}\text { Matéria seca (\%) } \\
\text { Dry matter }\end{array}$ & 91,57 & 91,92 & 91,81 & 91,85 \\
$\begin{array}{l}\text { Proteína bruta (\%) } \\
\text { Crude protein }\end{array}$ & 17,79 & 17,58 & 17,40 & 17,49 \\
$\begin{array}{l}\text { Lisina }(\%)^{2} \\
\text { Lysine }\end{array}$ & 0,89 & 0,83 & 0,77 & 0,72 \\
FDN $(\%)^{3}$ & 16,66 & 17,19 & 18,80 & 19,44 \\
NDF & 5,02 & 5,26 & 6,62 & 7,52 \\
FDA $(\%)^{4}$ & & & & \\
ADF & 4229 & 4232 & 4177 & 4165 \\
EB $(\mathrm{kcal} / \mathrm{kg})$ & & & & \\
$G E$ &
\end{tabular}

1 Dados obtidos no laboratório de Análise de Alimentos e Nutrição Animal/DZO/UEM.

2 Teor calculado, segundo NRC (1989).

$3 \mathrm{FDN}=$ fibra em detergente neutro; ${ }^{4} \mathrm{FDA}$ = fibra em detergente ácido.

1 Data obtained from Feed Analysis and Animal Nutrition Lab/DZO/UEM.

2 Calculated value in accordance with NRC (1989).

$3 \mathrm{NDF}=$ neutral detergent fiber; $A D F=$ acid detergent fiber. 


\section{Resultados e Discussão}

Os valores de pesos médios inicial (PMI) e final (PMF) e ganho médio diário (GMD) de eqüinos alimentados com diferentes níveis (\%) de substituição por farelo de canola estão demonstrados na Tabela 4 .

Os resultados obtidos para a característica de GMD não apresentaram efeito significativo, quando foram comparados os níveis de substituição da proteína bruta do farelo de soja pelo farelo de canola. Entretanto, observou-se tendência de redução de GMD, a partir do nível de inclusão de $65 \%$ de farelo de canola. A análise de regressão não demonstrou efeito dos níveis de inclusão do farelo de canola, em função do ganho de peso dos potros.

Os valores médios obtidos no presente trabalho para PMI $(218,4 \mathrm{~kg})$ e PMF $(270,25 \mathrm{~kg})$, em eqüinos de 9 a 11,5 meses, da raça Mangalarga, estiveram abaixo dos valores relatados por HINTZ et al. (1979), NRC (1989) e THOMPSON (1995). Estes autores, entretanto, utilizaram potros de raças exóticas, cujos valores encontrados, para PMI, foram 296, 299 e $315 \mathrm{~kg}$ e para PMF de 329,333 e $349 \mathrm{~kg}$, respectivamente. Entretanto, os animais utilizados no presente trabalho possibilitaram GMD de 691,8 g, valor este superior ao preconizado para eqüinos em crescimento, de $580 \mathrm{~g}$, proposto pelo NRC (1989) e CARVALHO (1995).

SAASTAMOINEN e KOSKINEN (1993), avaliando a qualidade protéica da dieta (alta e baixa) sobre o desempenho de potros da raça puro sangue inglês (PSI) de 7 a 12 meses de idade, encontraram GMD de $670 \mathrm{~g}$, para animais consumindo dieta de alta qualidade protéica. Valor similar de GMD foi obtido por WHITAKER e CARVALHO (1997), trabalhando com potros da raça Quarto de Milha (QM), com idade de 11,5 meses,

alimentados com concentrado contendo $17 \%$ de PB (usando a soja como fonte de proteína). Dessa forma, observa-se que o GMD obtido com os animais do presente trabalho demonstra que todos os níveis de substituição do farelo de canola proporcionaram ótimo desempenho, quanto ao crescimento dos eqüinos.

SUTTON e STREDWICK (1979) apresentaram resultados concordantes ao do presente estudo, no qual indicaram a substituição total da proteína bruta do farelo de soja pelo farelo de canola, em que a inclusão do farelo de canola não afetou adversamente o GMD. Esses autores relataram GMD de $1,11 \mathrm{~kg}$, entretanto utilizaram animais com idade superior (12 a 14 meses) ao do presente trabalho.

Da mesma forma, CYMBALUK (1990), trabalhando com potros de tração com 6 a 12 meses de idade, alimentados com dietas contendo $16 \%$ de PB, formuladas com substituição total do farelo de soja pelo farelo de canola, apresentou resultados favoráveis quanto à substituição total da proteína bruta do farelo de soja pelo farelo de canola. O valor encontrado para GMD foi de $825 \mathrm{~g}$, ligeiramente superior ao obtido no presente estudo.

Na Tabela 5, estão apresentados os valores obtidos para desenvolvimento de eqüinos alimentados com dietas contendo diferentes níveis de farelo de canola.

Os valores obtidos para altura na cernelha, perímetro torácico e perímetro de canela não sofreram efeito $(\mathrm{P}>0,05)$ dos níveis de substituição da proteína bruta do farelo de soja pelo farelo de canola, porém tenderam a reduzir a partir do nível de inclusão de $65 \%$ de farelo de canola.

Os valores dos parâmetros de crescimento obtidos com os animais do presente trabalho, tanto inicial quanto final, apresentaram-se abaixo das estimativas de crescimento preconizado e obtidos para animais

Tabela 4 - Pesos médios inicial (PMI) e final (PMF) e Ganho médio diário(GMD - g/anim.dia) em eqüinos alimentados com dietas contendo diferentes níveis (\%) de substituição do farelo de soja por farelo de canola (FC)

Table 4 - Average initial (IAW) and final (FAW) weight and average daily gain (ADG - g/anim.day) in equines fed diets with different soybean meal replacement levels (\%) by canola meal (CM)

\begin{tabular}{|c|c|c|c|c|c|c|}
\hline $\begin{array}{l}\text { Variável } \\
\text { Variable }\end{array}$ & $\begin{array}{l}0-\mathrm{FC} \\
0-C M\end{array}$ & $\begin{array}{l}35-\mathrm{FC} \\
35-C M\end{array}$ & $\begin{array}{l}\text { 65-FC } \\
65-C M\end{array}$ & $\begin{array}{l}100-\mathrm{FC} \\
100-C M\end{array}$ & $\begin{array}{l}\mathrm{p} \text {-value } \\
\text { p-value }\end{array}$ & $\mathrm{CV}(\%)$ \\
\hline PMI (kg) & 210,50 & 200,00 & 228,13 & 234,88 & & \\
\hline $\begin{array}{l}I A W(\mathrm{~kg}) \\
\mathrm{PMF}(\mathrm{kg}) \\
F A W(K G)\end{array}$ & 264,25 & 253,00 & 280,13 & 283,63 & & \\
\hline $\begin{array}{l}\mathrm{GMD}(\mathrm{g}) \\
A D G(g)\end{array}$ & 717 & 707 & 693 & 650 & 0,85 & 16,75 \\
\hline
\end{tabular}

\footnotetext{
${ }^{1} \mathrm{CV}=$ Coeficiente de variação (Coefficient of variation).
} 
178 Rev. bras. zootec.

Tabela 5 - Desenvolvimento ponderal de eqüinos alimentados com dietas contendo diferentes níveis (\%) de substituição de farelo de soja por farelo de canola (FC)

Table 5 - Ponderal development of equines fed diets with different soybean meal replacement levels (\%) by canola meal (CM)

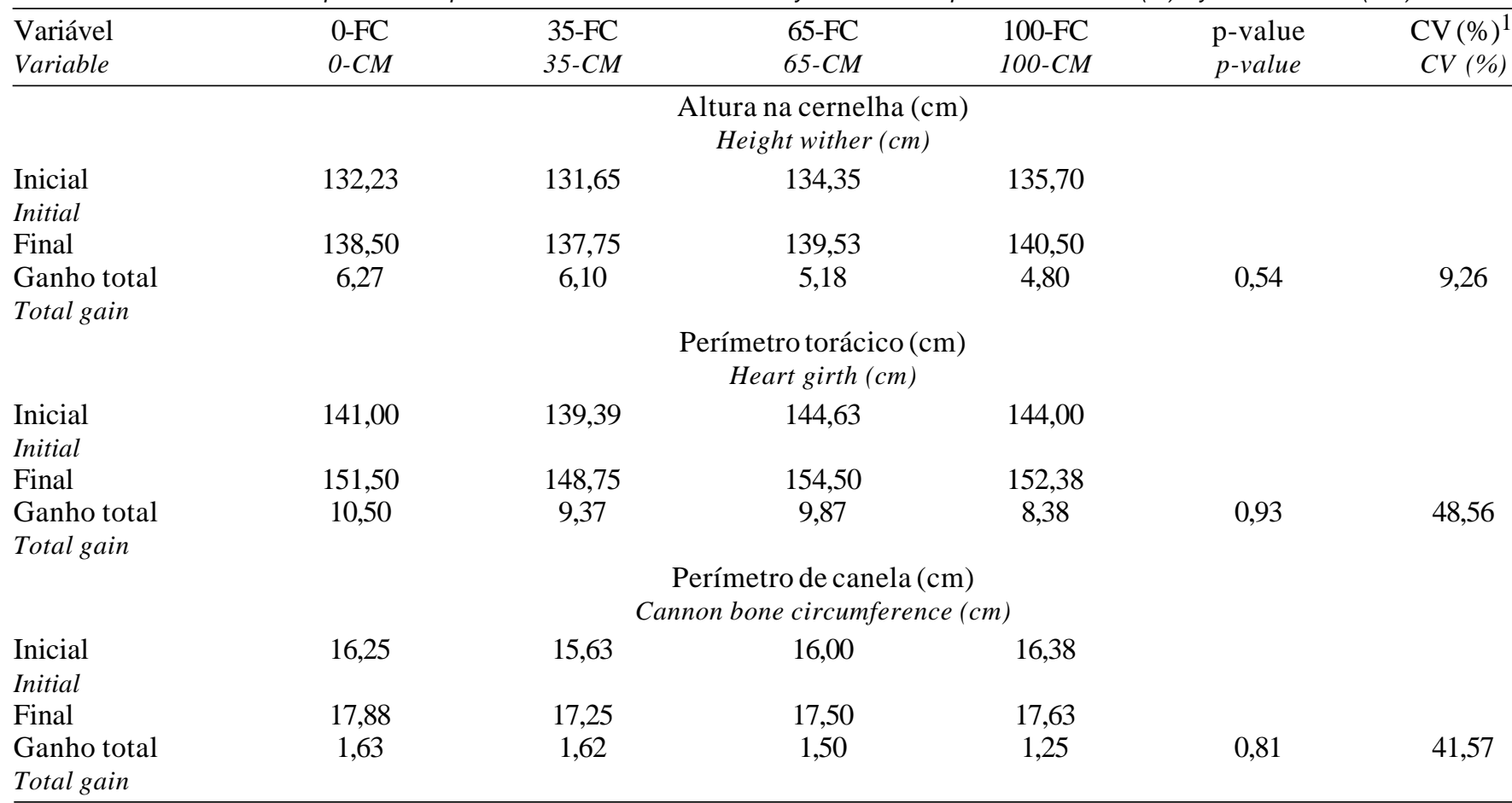

${ }^{1} \mathrm{CV}=$ Coeficiente de variação (Coefficient of variation).

de raças exóticas (HINTZ et al., 1979; SAASTAMOINEN e KOSKINEN, 1993; SAASTAMOINEN et al., 1994; THOMPSON, 1995). Entretanto, o ganho total de AC e PC obtido na presente pesquisa foi superior aos relatados por HINTZ et al. (1979) e GRAHAM et al. (1994), que observaram valores médios de 4,9 e 1,0 cm, respectivamente, trabalhando com potros da raça PSI com 7 a 12 meses de idade.

Em outro ensaio avaliando potros da raça Finnhorse de 7 a 12 meses de idade, SAASTAMOINEN e KOSKINEN (1993) e SAASTAMOINEN et al. (1994) observaram valores para ganho total de AC de 8 a $11,4 \mathrm{~cm}$ e PT de 13,9 a $14,8 \mathrm{~cm}$, superiores aos resultados obtidos na presente pesquisa.

WHITAKER et al. (1995), trabalhando com potros da raça QM com 14 meses e PV médio de $244 \mathrm{~kg}$ (durante 92 dias), encontraram resultados semelhantes aos desta pesquisa. Portanto, não se encontraram diferenças significativas para as características relativas ao crescimento de potros, entre os animais consumindo concentrado com $18 \%$ de PB, contendo diferentes fontes protéicas (farelo de soja ou levedura de cana), cujos valores observados para o ganho total de AC e PT foram de 3 e $19 \mathrm{~cm}$, respectivamente.
Em pesquisa conduzida por WHITAKER e CARVALHO (1997), trabalhando com potros da raça $\mathrm{QM}$, com 11,5 meses de idade, recebendo concentrado com 17,5\% de PB (utilizando farelo de soja como fonte protéica), observaram-se valores próximos aos encontrados no presente estudo, para o ganho total de AC $(5 \mathrm{~cm})$ e para o PT $(10 \mathrm{~cm})$.

As médias dos parâmetros sangüíneos de glicose e uréia, em eqüinos alimentados com diferentes níveis (\%) de substituição por farelo de canola, estão apresentadas na Tabela 6.

Como demonstram os resultados, não foram detectadas diferenças significativas nos teores de glicose e uréia, entre os animais alimentados com ração contendo diferentes níveis de substituição da proteína bruta do farelo de soja pelo farelo de canola.

Segundo FRAPE (1998), as concentrações sangüíneas normais de glicose (obtidas de 1,5 a 3,0 horas após alimentação) e uréia, para eqüinos, variaram de 117 a $153 \mathrm{mg} / \mathrm{dL}$ e 21,4 a $51,36 \mathrm{mg} / \mathrm{dL}$, respectivamente. Os teores de glicose observados no presente estudo foram superiores aos obtidos por SAASTAMOINEN e KOSKINEN (1993) e SAASTAMOINEN et al. (1994), cujos valores mais freqüentes variaram de 89,0 a $107,9 \mathrm{mg} / \mathrm{dL}$ para 
OLIVEIRA et al.

Tabela 6 - Parâmetros sangüíneos médios de glicose e uréia em eqüinos alimentados com dietas contendo diferentes níveis (\%) de farelo de canola (FC).

Table 6 - Blood parameters of glucose and urea of the equines fed with different soybean meal replacement levels (\%) by canola meal (CM)

\begin{tabular}{|c|c|c|c|c|c|c|}
\hline Variável & $0-\mathrm{FC}$ & $35-\mathrm{FC}$ & $65-\mathrm{FC}$ & $100-\mathrm{FC}$ & p-value & $\mathrm{CV}(\%)^{1}$ \\
\hline Variable & $0-C M$ & $35-C M$ & $65-C M$ & $100-C M$ & p-value & $C V(\%)$ \\
\hline $\begin{array}{l}\text { Glicose }(\mathrm{mg} / \mathrm{dL}) \\
\text { Glucose }(\mathrm{mg} / \mathrm{dL})\end{array}$ & 133,50 & 126,96 & 129,46 & 130,50 & 0,60 & 15,62 \\
\hline $\begin{array}{l}\text { Uréia }(\mathrm{mg} / \mathrm{dlL} \\
\text { Urea }(\mathrm{mg} / \mathrm{dL})\end{array}$ & 41,08 & 46,54 & 45,00 & 47,08 & 0,20 & 10,10 \\
\hline
\end{tabular}

${ }^{1} \mathrm{CV}=$ coeficiente de variação (coefficient of variation).

potros de 215 dias, porém são concordantes aos valores encontrados por FRAPE (1998).

A concentração de uréia obtida na presente pesquisa apresentou-se dentro dos valores considerados normais e semelhantes aos de outros estudos (SAASTAMOINEN e KOSKINEN, 1993; GRAHAM et al., 1994; SAASTAMOINEN et al., 1994).

Em experimento com potros de tração com dez meses de idade, CYMBALUK (1990) observou resultado discordante do presente trabalho, no que se refere à concentração de uréia. Em dietas contendo farelo de canola ou farelo de soja, esses autores relataram valor médio de 27,1 e $31,3 \mathrm{mg} / \mathrm{dL}$, respectivamente, com diferença significativa entre as fontes protéicas avaliadas.

Observando-se a Figura 1, nota-se que os valores de glicose e uréia, inicial e final, também não diferiram $(\mathrm{P}>0,05)$.

A concentração de uréia plasmática obtida no presente estudo indica que o suprimento protéico foi adequado para potros de 9 a 11,5 meses de idade. Contraditoriamente, CYMBALUK (1990) relatou que dietas contendo $16 \%$ de PB excederam as exigências protéicas de potros com 10 meses de idade, embasado na elevação do teor de uréia plasmática, cuja concentração inicial, de $25,5 \mathrm{mg} / \mathrm{dL}$, elevou-se para $37,2 \mathrm{mg} / \mathrm{dl}$, ao final do experimento, para animais consumindo ração contendo farelo de soja e de 22,3 para $32,3 \mathrm{mg} / \mathrm{dL}$, para animais consumindo ração contendo farelo de canola.

\section{Conclusões}

O desempenho dos animais quanto aos parâmetros ganho de peso vivo, altura na cernelha, perímetro torácico e perímetro da canela não foi afetado pela substituição do farelo de soja pelo farelo de canola

Os concentrados para potros dos 9 a 11,5 meses de idade podem ser formulados com substituição total da proteína bruta do farelo de soja pelo farelo de canola.

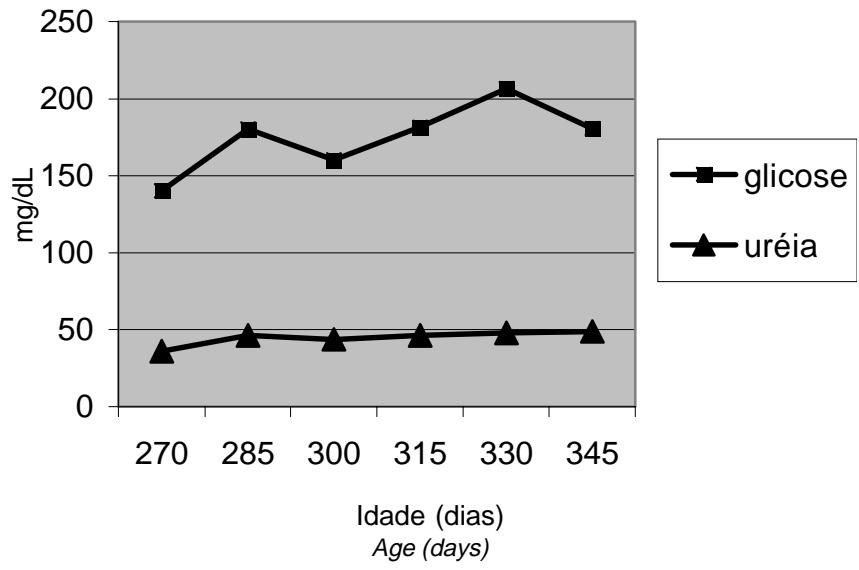

Figura 1 - Concentrações sangüíneas de glicose e uréia de equinos alimentados com diferentes níveis (\%) de substituição por farelo de canola.

Figure 1 - Blood concentration of glucose and urea of equines fed diets with different levels (\%) of canola meal (CM) replacement.

\section{Referências Bibliográficas}

ASSOCIATION OF OFFICIAL ANALYTICAL CHEMIST AOAC. 1980. Official methods of the analysis. 13.ed. Washington, DC. $1018 \mathrm{p}$.

BELL, J.M. 1993. Factors affecting the nutritional value of canola meal: a review. Can J. Anim. Sci., 73:679-697.

BELL, J.M., KEITH, M.D. 1991. A survey of variation in the chemical composition of comercial canola meal produced in western Canadian crushing plants. Can J. Anim. Sci., 71(2):469-480.

CARVALHO, M.L.S. 1995. Cuidado com o crescimento dos seus potros. R. Criadores. 35 p.

CASTELL, A.G., CLIPLEF, R.L.1993. Evaluation of pea screenings and canola meal as a supplementary protein source in barley - based diets fed to growing-finishing pigs. Can J. Anim. Sci., 73(1):129-139.

COCHRAN, W.G., COX, G.M. 1967. Experimental designs. New York: John Wiley and Sons. p.617.

CYMBALUK, N.F. 1990. Using canola meal in growing draft horse diet. Eq. Pract., 12(4):13-19. 
180 Rev. bras. zootec.

FRAPE, D. 1998. Equine nutrition and feeding. 2.ed. Oxford: Blackwell Science Ltda. 564p.

GRAHAM, P.M., OTT, E.A., BRENDEMUHL, J.H. et al. 1994. The effect of supplemental lysine and threonine on growth and development of yearling horses. J. Anim. Sci., 72:380-396.

HINTZ, H.F., HINTZ, R.L., VLECK, L.D.V. 1979. Growth rate of thoroughbreds. Effects of age of dam, year and month of birth, and Sex of foal. J. Anim. Sci., 48(3):480-487.

KAPLAN, L.A., PESCE, A.J. 1988. Quimica clinica. Teoría, análisis y correlacion. Buenos Aires: Editorial Medica Panamericana. 1491p.

LACERDA, P.C. 1973. Estudo biométrico dos equinos puro sangue inglês. Anuário do Turfe Criação, 1(1):38-46.

LEWIS, L.D. 1995. Equine clinical nutrition. Feeding and care. 1.ed., Philadelphia: Williams e Wilkins. 587p.

NATIONAL RESEARCH COUNCIL - NRC. 1989. Requeriments of domestic animals. Nutrient requeriments offorses. 5.rev.ed. Washington: National Academy of Sciences. 100p.

OTT, E.A. 1995. Dietary nutrient allowances for horses. Feedstuffus, 64(29):77-80.

ROGERS, P.A. FAHEY, G.C., ALBERT, W.W. 1984. Blood metabolite profiles of broodmares and foals. Eq. Vet. J., 16:192-196.

SAASTAMOINEN, M.T., KOSKINEN, E.1993. Influence of quality of dietary protein supplement and anabolis steroids on muscular and skeletal growth of foals. Anim. Prod., 56:135-144.

SAASTAMOINEN, M.T., HYYPPA, S. HUOVINEN, K. 1994. Effect of dietary - fat supplementation and energy to protein ratio on growth and blood metabolites of wealing foals. J. Anim. Physiol. Anim. Nutr., 71:179-188.
STATISTICAL ANALYSIS SYSTEM. 1986. SAS system for linear models. Cary: SAS Institute. 211p.

SUTTON, E.I., STREDWICK, R.V. 1979. Acceptance of rapeseed meal (cv. Candle) by horses. Can J. Anim. Sci., 50(4):819-820.

THOMPSON, K.N. 1995. Skeletal growth rates of wealing and yearling thoroughbred horses. J. Anim. Sci., 73(9):2513-2517.

TRINDER, P. 1969. Determination of glucose in blood using glucose oxidase with an alternative oxygen acceptor. Ann. Clin. Biochem., 6:L24-27.

WHITAKER, H.M.A., SILVA, A.E.D., MANZANO, A. et al. 1995. Utilização da levedura seca (Saccharomyces cerevisae) de álcool de cana-de-açúcar em rações para eqüinos. R. Bras. Zootec., 24(6):1008-1015.

WHITAKER, H.M.A., CARVALHO, R.L. 1997. Substituição do milho pelo sorgo em rações para eqüinos. R. Bras. Zootec., 26(1):139-143.

Recebido em: 06/09/99

Aceito em: 21/09/00 